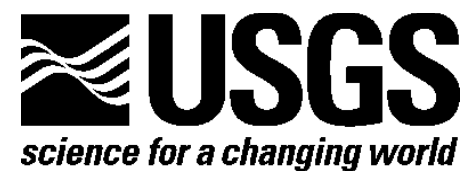

Prepared as part of the U.S. Geological Survey Priority Ecosystems Science Initiative

\title{
Joint Ecosystem Modeling (JEM) Ecological Model Documentation Volume 2: Roseate Spoonbill (Platalea ajaja) Landscape Habitat Suitability Index v1.0.0
}

By Stephanie S. Romañach, Craig Conzelmann, Adam Daugherty, Jerome J. Lorenz, Christina Hunnicutt, and Frank J. Mazzotti

Open-File Report 2011-1273 


\section{U.S. Department of the Interior \\ KEN SALAZAR, Secretary}

\section{U.S. Geological Survey \\ Marcia K. McNutt, Director}

U.S. Geological Survey, Reston, Virginia 2011

For product and ordering information:

World Wide Web: http://www.usgs.gov/pubprod

Telephone: 1-888-ASK-USGS

For more information on the USGS-the Federal source for science about the Earth,

its natural and living resources, natural hazards, and the environment:

World Wide Web: http://www.usgs.gov

Telephone: 1-888-ASK-USGS

Suggested citation:

Romañach, S.S., Conzelmann, Craig, Daugherty, Adam, Lorenz, J.L., Hunnicutt, Christina, and Mazzotti, F.J., 2011, Joint Ecosystem Modeling (JEM) Ecological Model Documentation Volume 2: Roseate Spoonbill (Platalea ajaja) Landscape Habitat Suitability Index v1.0.0: U.S. Geological Survey Open-File Report 2011-1273, 23 p.

Any use of trade, product, or firm names is for descriptive purposes only and does not imply endorsement by the U.S. Government.

Although this report is in the public domain, permission must be secured from the individual copyright owners to reproduce any copyrighted material contained within this report. 


\section{Acknowledgments}

We appreciate the input received from many individuals from our partner agencies, organizations, and universities who participated in a workshop to help improve the model. Thanks is extended to Kevin Chartier for programming support. We appreciate the time spent by two anonymous reviewers whose comments resulted in a better product.

We are grateful the Advanced Applications Group at the National Wetlands Research Center for providing a platform (EverVIEW) for viewing and examining the model inputs and outputs. Many thanks to G. Ronnie Best and Greater Everglades Priority Ecosystems Science for funding to develop the software. 


\section{Contents}

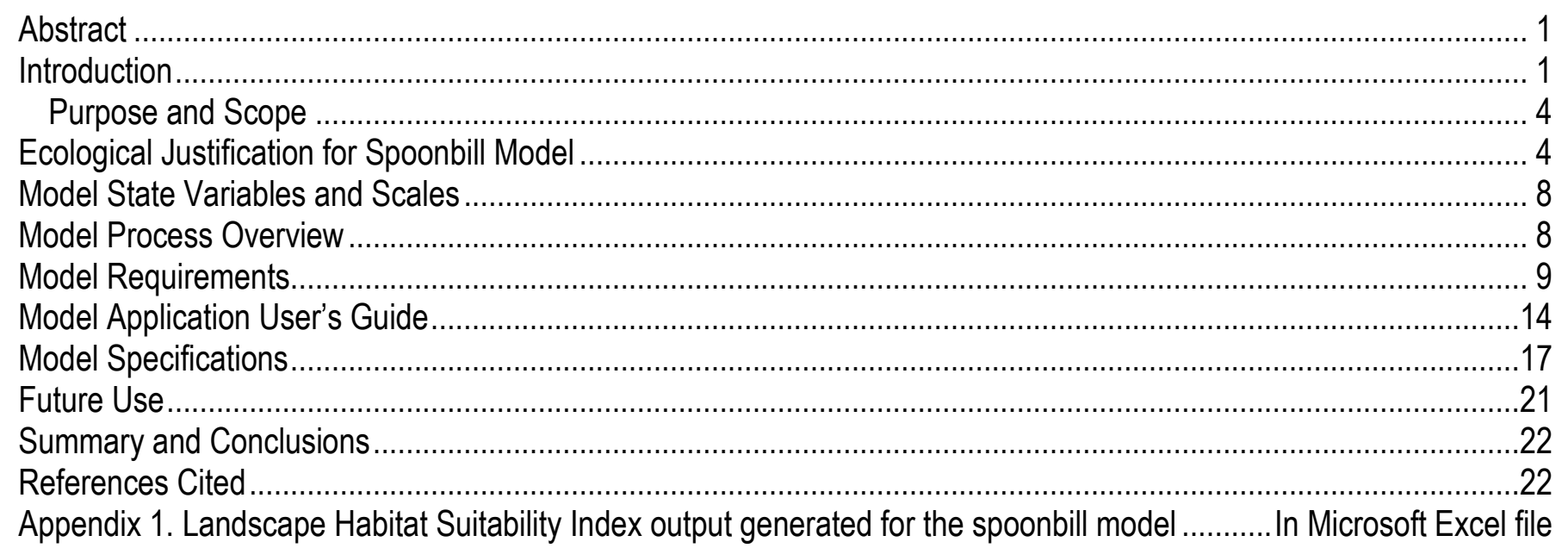

\section{Figures}

Figure 1. Schematic illustration of water flow in the Greater Everglades ........................................................... 1

Figure 2. Map showing output from the Prey Availability Index for the spoonbill model in northeastern Florida Bay. .. 5

Figure 3. Map showing output from the Prey Availability Index for the spoonbill model on December 29, 1999........11

Figure 4. Map showing output from the Prey Abundance \& Availability Index for the spoonbill model on December 29. 1999

Figure 5. Map showing output from the Habitat Suitability Index (HSI) for the spoonbill model showing the HSI values changing through time on December 29, 1997; December 29, 1998; and December 29, 1999 ....13

Figure 6. Application screenshot of files required to run the spoonbill model and produce output.............................14

\section{Tables}

Table 1. Prey Availability Index for the spoonbill model based on water depth, in centimeters. ................................. 6

Table 2. Prey Availability Index scores for the spoonbill model based on water depths. .......................................... 6

Table 3. Inputs needed to generate spoonbill model results. ………………………………............................... 9

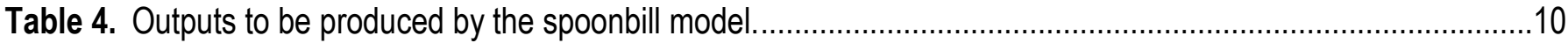

Table 5. Variables in the output NetCDF file which correspond to the spoonbill model inputs and outputs.................20 


\title{
Joint Ecosystem Modeling (JEM) Ecological Model Documentation Volume 2: Roseate Spoonbill (Platalea ajaja) Landscape Habitat Suitability Index v1.0.0
}

By Stephanie S. Romañach¹, Craig Conzelmann², Adam Daugherty ${ }^{3}$, Jerome J. Lorenz ${ }^{4}$, Christina Hunnicutt², and Frank J. Mazzotti ${ }^{3}$

\begin{abstract}
Ecological conditions in the Greater Everglades have changed due to human activities, including the construction of canals to divert water away from the core of the landscape. Current and planned restoration projects are designed to produce a natural sheetflow of water across the landscape. This restoration of water flow should provide an increase in freshwater needed to restore natural salinities to the fringing estuarine ecosystem. In this report, we describe a Landscape Habitat Suitability Index model designed to evaluate alternative restoration plans for the benefit of a key species, the roseate spoonbill (Platalea ajaja). Model output has shown to be a good indicator of areas capable of supporting spoonbills. Use of this model will allow examination of the potential response of this key species to water management proposed through the Greater Everglades restoration process.
\end{abstract}

\section{Introduction}

Development for human needs in southern Florida has led to a system of canals being constructed with the result of diverting fresh water away from much of the Greater Everglades ecosystem, including freshwater flow into the estuaries and coasts at its fringes (fig. 1). The Comprehensive Everglades Restoration Plan (CERP) presented to Congress in July 1999 (U.S. Army Corps of Engineers and South Florida Water Management District, 1999) recommends over 60 projects with the goal of restoring predevelopment natural water flow across the Greater Everglades. The restoration of natural water flow should improve water quality and lead to more natural hydroperiods across the landscape.

\footnotetext{
${ }^{1}$ Southeastern Ecological Science Center, U.S. Geological Survey

${ }^{2}$ National Wetlands Research Center, U.S. Geological Survey

${ }^{3}$ Fort Lauderdale Research and Education Center, University of Florida

${ }^{4}$ Audubon of Florida
} 

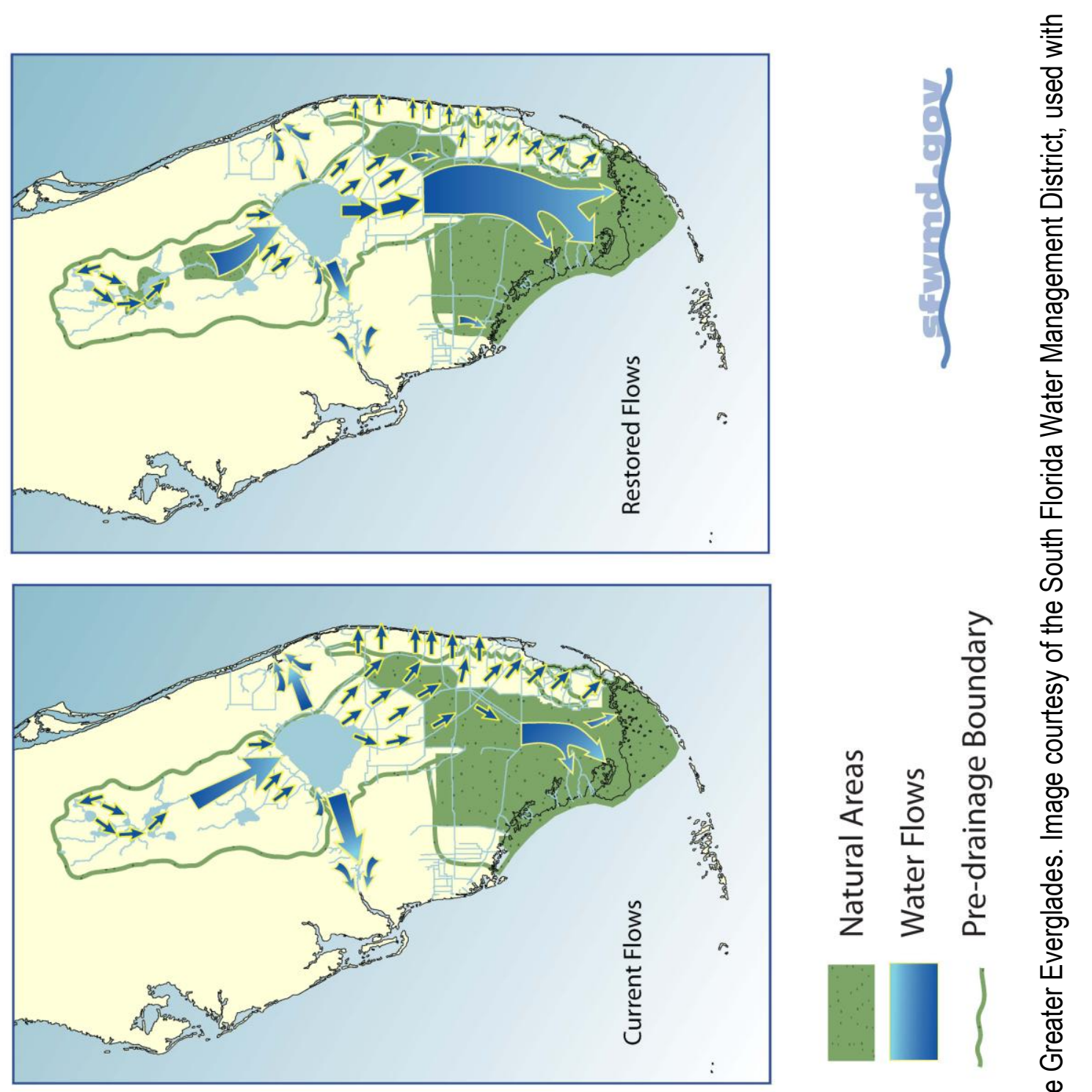



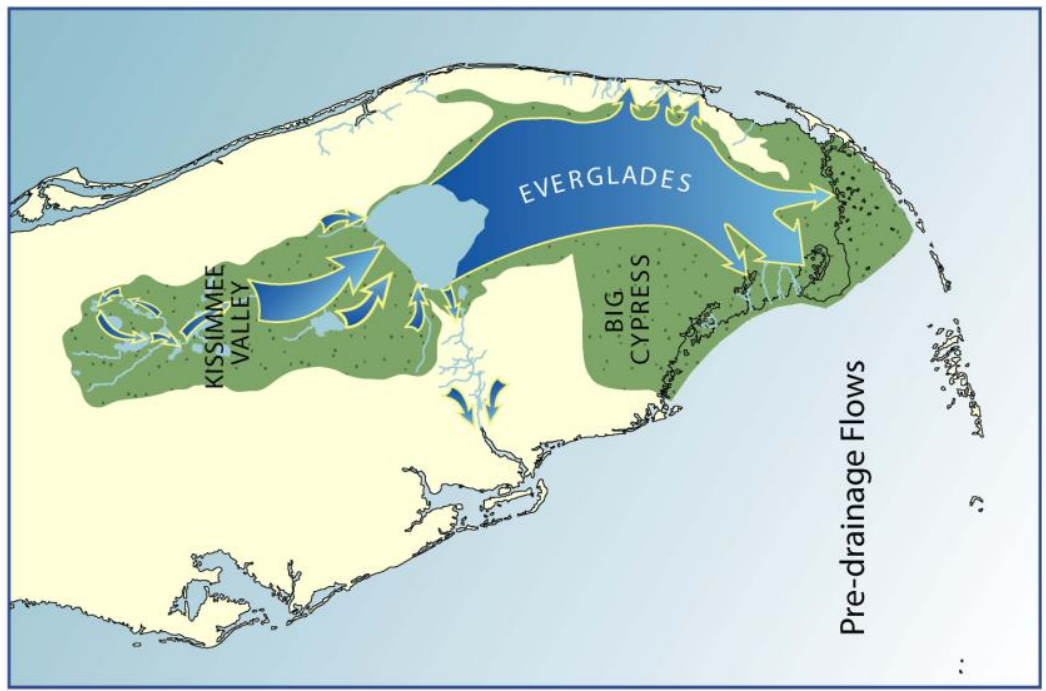


Freshwater flow into the coastal areas of southern Florida once provided conditions necessary for the persistence of estuarine fauna and flora. After inland canals and water control structures were constructed, water delivery to areas of northeastern Florida Bay changed dramatically (Light and Dineen, 1994; McIvor and others, 1994; Lorenz, 2000). In recent decades, Florida Bay has experienced major changes in salinity, vegetation, flora, and fauna, causing many species population changes. One of the major restoration goals for Florida Bay is to restore freshwater discharge into the eastern and central bay areas. Planned restoration projects will affect salinity and water depth both spatially and temporally.

To assist in restoration planning, ecological models were developed as an evaluation tool to aid in the determination of an acceptable range of factors, such as salinity and water depth, as they relate to the persistence of key fauna. These models can be used to select among alternative restoration plans that provide the most suitable conditions for a given species.

Previous work by Gawlik (2001) led to the development of an HSI for wood storks and white ibis that focused on prey availability during the nesting period. Hydrologic patterns that produce the maximum number of high-density prey patches result in good nesting efforts for wood storks, white ibises, and roseate spoonbills (Smith and Collopy, 1995; Gawlik, 2002). Lorenz and others (2002) found that both high water conditions during the wet season and low water levels during the dry season contribute to the availability of prey for nesting roseate spoonbills. At the time of development of a HSI by Gawlick (2001), the data needed to incorporate estimates of initial prey density were unavailable. The prey base of spoonbills nesting in northeastern Florida Bay has been extensively studied (Lorenz and others, 1997; Lorenz, 1999, 2000), allowing for the incorporation of hydrologic conditions that favor high prey production into a spoonbill HSI for northeastern Florida Bay. Additionally, based on extensive aerial surveys by Bjork and Powell (1994) we incorporate distance from the nest to an adequate food supply into the Landscape HSI presented in this report.

To assist in restoration planning, ecological models were developed by the U.S. Geological Survey (USGS) and others as an evaluation tool to help determine an acceptable range of conditions, such as water depth, as they relate to the persistence of key fauna. These models can be used to select among alternative restoration plans that provide the most suitable conditions for a given species.

The purpose of the Roseate Spoonbill Landscape Habitat Suitability Index Model (hereafter, -spoonbill model") is to portray the response of the roseate spoonbill to changes in salinity and water depth, which will result from restoration activities. Roseate spoonbills were selected for modeling because they are ecologically and recreationally important, and have a well-established linkage to stressors (salinity and water depth) of interest to natural resource managers. Because of their highly specialized foraging behavior, spoonbills may be more sensitive to disruptions in the wet/dry cycle compared to other predatory species dependent on Florida Bay's coastal wetlands. It is this sensitivity that makes the roseate spoonbill a good candidate for biological monitoring in this system.

The model described herein helps contribute to USGS terrestrial, freshwater, and marine environments ecosystem science. Specifically, the model allows users to (1) understand the ecosystem and how various factors control suitable habitat for roseate spoonbill persistence, and (2) predict future changes as Greater Everglades restoration progresses. 


\section{Purpose and Scope}

The purpose of this report is to describe a Landscape Habitat Suitability Index (HSI) model for roseate spoonbills (Platalea ajaja). The model is based on three main inputs: water depth, prey biomass, and nest location. The resulting Landscape HSI value represents the best quality habitat to support roseate spoonbills. HSI models have been commonly used for environmental evaluations (U.S. Fish and Wildlife Service, 1981) and for ecosystem restoration projects, as an approximate means of quantifying the effects of restoration projects on species habitats (Barnes and others, 2006). A HSI value of one indicates that the habitat component is sufficient for colonization, breeding, and population growth to the maximum potential abundance, and a value of zero means the habitat is unsuitable for the species.

Model results are given for the entire geographic domain of the water depth and salinity inputs, all of which are from the Tides and Inflows in the Mangroves of the Everglades (TIME) model (Wang and others, 2007); however, the model described herein is designed to be used for the population of roseate spoonbills nesting in Florida Bay.

The information presented in this report is divided into six major sections:

1. Model Ecological Justification: Provides ecological background for model rules.

2. Model State Variables and Scales: Provides descriptions of model entities being used or computed.

3. Model Process Overview: Provides the steps and order of model computations.

4. Model Requirements: Describes the rules that define the model. It is intended to be used by subject matter experts and modelers to evaluate model rules and by software engineers as a part of the analysis phase of software development.

5. Model Application User's Guide: Describes how to use the model application to generate model results. It is intended to be used by managers, decision makers, or anyone who wishes to generate model results.

6. Model Specifications: Provides information related to design of the model application, limitations of model application and data, formats for inputs and outputs, and extension and adaptation of the model. It is intended to provide coding details relevant to software developers.

\section{Ecological Justification for Spoonbill Model}

Foraging Proximity Index - A foraging proximity index is calculated across the landscape from the distance of the centroid of each landscape cell to the closest known nesting location, according to the mapping description in table 1 (Lorenz and others, 2002). The only nest location in the current model implementation is Tern Key (fig. 2). The coordinate used for Tern Key is 545150, 2782750, as referenced to Universal Transverse Mercator (UTM) zone 17R, North American Datum of 1983 (NAD 83). 


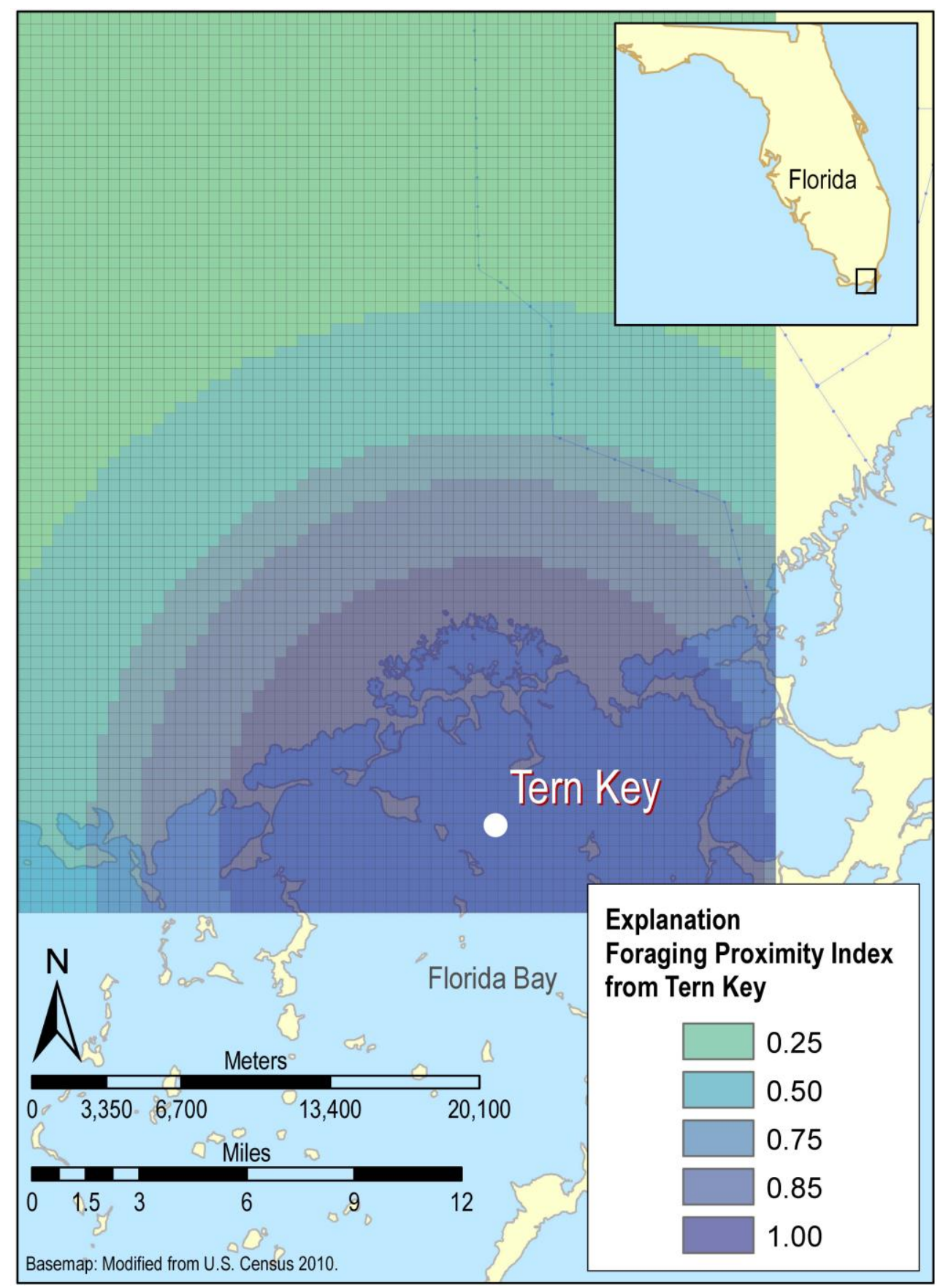

Figure 2. Map showing output from the Prey Availability Index for the spoonbill model in northeastern Florida Bay. Proximity to Tern Key yields higher Index values 
Table 1. Prey Availability Index for the spoonbill model based on water depth, in centimeters.

[km, kilometer; std. dev., standard deviation; \%, percent]

\begin{tabular}{ccl}
\hline $\begin{array}{c}\text { Minimum distance from } \\
\text { cell centroid to any } \\
\text { spoonbill nest } \\
(\mathbf{k m})\end{array}$ & $\begin{array}{c}\text { Foraging proximity } \\
\text { Index }\end{array}$ & \multicolumn{1}{c}{ Reason for relation } \\
\hline$<12.4$ & 1 & Mean foraging flight distance \\
$12.4-16$ & .85 & $85 \%$ of flights less than $16 \mathrm{~km}$ \\
$16-18.2$ & .75 & Mean +1 std. dev. \\
$18.2-24$ & .5 & Mean +2 std. dev. \\
$\geq 24$ & .25 & $>$ Mean +2 std. dev. \\
\hline
\end{tabular}

Prey Availability Index - Powell (1987) demonstrated that roseate spoonbills cannot forage at water depths greater than 20 centimeters $(\mathrm{cm})$, setting an upper foraging depth limit for the HSI. In the coastal wetlands of northeastern Florida Bay, when water levels recede to $20 \mathrm{~cm}$ below the wetland surface $(-20 \mathrm{~cm}$ depth), the majority of the remaining wetted fish refugia become dry, thereby setting the lower foraging depth limit (J. Lorenz, unpub. data, 2011). Between these extremes, prey fish availability varies depending on water depth on the wetland surface.

Lorenz (1997) subdivided the coastal wetlands of northeastern Florida Bay into two subhabitats - deep creek and marsh flat — with the latter being the ephemeral wetland that dries out during the dry season and the former being the deeper refugia fish evacuate to when the flats become dry. The water level at which the flats were completely dry and the creeks were completely inundated was assigned a relative depth of zero. At this depth, approximately 60 to 90 percent of the wetland is dry $(\mathrm{J}$. Lorenz, data, 2011). At a relative depth of $-10 \mathrm{~cm}$, only about 5 percent of the wetland remains inundated. At a relative depth of about $6 \mathrm{~cm}$, significant portions of the flats become dry, and at depths greater than $8 \mathrm{~cm}$, the flats are fully inundated. Lorenz (2000) demonstrated that fish begin to evacuate the flats and take refuge in deeper habitats when water levels drop to a relative depth of about $13.1 \mathrm{~cm}$. At greater depths, adult spoonbills can feed themselves, but are severely hampered in providing sufficient prey to support the energetic demands of their chicks (Lorenz, 2002). Based on these findings and the available data, each model cell will be assigned a model coefficient based on the water depth at any given time, as specified in table 2 .

Table 2. Prey Availability Index scores for the spoonbill model based on water depths. [cm, centimeter]

\begin{tabular}{ccl}
\hline $\begin{array}{c}\text { Relative water depth } \\
(\mathbf{c m})\end{array}$ & $\begin{array}{c}\text { Prey availability } \\
\text { Index }\end{array}$ & \multicolumn{1}{c}{ Reason for depth category } \\
\hline$\geq 20$ & 0 & Too deep to forage \\
$13.1-20$ & .25 & Prey not concentrated \\
$6-13.1$ & .75 & Prey concentrated; flats still flooded \\
$-10-6$ & 1 & Flats dry, optimum concentration \\
$-20--10$ & .75 & Limited wetted area remaining \\
$<-20$ & 0 & Wetland dry \\
\hline
\end{tabular}


Prey Abundance \& Availability Index - The prey biomass model uses depth and salinity inputs to model total biomass and availability of biomass of fish (standing stock) that are prey for spoonbills.

Total prey biomass is modeled using equation 1 (Lorenz, 1999; Romañach and others, 2011):

$$
\begin{aligned}
& 1.01+ \\
& 0.0013 \cdot(\text { number of days of last } 90 \text { that salinity was less than } 5 \mathrm{ppt})+ \\
& 0.037 \cdot(\text { mean depth of last } 300 \text { days, in } \mathrm{cm})+ \\
& (-0.041) \cdot(\text { standard deviation of depth for past } 90 \text { days, in } \mathrm{cm})+ \\
& (-0.02) \cdot(\text { current day depth, in } \mathrm{cm})+ \\
& (-0.01) \cdot(\text { number of days of last } 60 \text { that depth was less than } 5 \mathrm{~cm})+ \\
& 0.0013 \cdot(\text { number of continuous days with depth greater than } 13.1 \mathrm{~cm})
\end{aligned}
$$

To allow for comparison among maps from a single model run and across a set of model runs, biomass is scaled according to the maximum biomass value across the set of model runs. The resulting scaled biomass has a range of 0 to 1 . The index is described by equation 2 :

$$
\frac{(r-n)}{(m-n)}
$$

where $r$ is the biomass, $n$ is the minimum biomass in all cells for all days, and $m$ is the maximum biomass in all cells for all days.

The Prey Abundance and Availability Index is then calculated as a weighted geometric mean of biomass and availability as described by equation 3 :

$$
\text { Prey Abundance \& Availability Index }=\text { Biomass }^{\frac{2}{5}} \bullet \text { Availability }^{\frac{3}{5}}
$$

where Biomass is the Biomass Index input for the time step, Availability is the Prey Availability Index for the time step, and all exponentiations and multiplications are performed cell-wise.

Habitat Suitability Index - Each of the main components (Prey Abundance and Availability Index and Foraging Proximity Index) can be calculated for each model cell for a given time step. Each of these is of critical importance to a nesting spoonbill and an unfavorable condition in any one of the three could result in nest failure; therefore, the relationship between the main components is multiplicative. However, the two indices are not of equal weighting. The most critical factor is Prey Abundance and Availability followed by Foraging Proximity; therefore, the components will be weighted as described by equation 2 . Prey Abundance \& Availability is weighted more heavily than Foraging Proximity because spoonbills are highly mobile and can travel to find prey. Mean foraging flight distance is approximately 12.4 kilometers $(\mathrm{km})$ (Lorenz, 2002), which is not a great distance or energetic cost for the species; therefore, Proximity is weighted to be of less importance than Abundance.

$$
\text { Habitat Suitability Index }=\text { Abundance }^{\frac{5}{6}} \bullet \text { Proximity }^{\frac{1}{6}}
$$

where Abundance is the Prey Abundance \& Availability Index for the time step, Proximity is the Foraging Proximity Index for the time step, and all exponentiations and multiplications are performed cell-wise. 
Landscape HSI-The Landscape HSI is calculated based on the highest quality foraging areas available to spoonbills. Spoonbills are highly mobile and move (in a non-random pattern) across the landscape to the best foraging locations. These highest quality areas preferred by spoonbills compose approximately 23 percent of the landscape (J. Lorenz, written commun., 2010). The Landscape HSI is calculated by calculating the average HSI value for the top 23 percent of cells in terms of quality.

\section{Model State Variables and Scales}

- Hydrology/Water Depth: Varies by grid cell and daily time step. Each grid cell contains a water depth value, in meters, for each day.

- Prey Biomass Index: Varies by grid cell and daily time step and is a result of the Estuarine Prey Fish Biomass Availability model (v1.0.0). Index values range between 0 and 1 (inclusive). The index represents the likelihood of fish biomass occurring at each cell.

- Nest Location: A static variable assigned the easting and northing of a known roseate spoonbill nest location.

- Nest Proximity: Varies by grid cell only. Nest proximity is represented in meters, and specifies the distance from the nest location used in the model.

- Foraging Proximity Index Nest Location: Varies by grid cell only. The index value ranges between 0 and 1 (inclusive), and represents the likelihood of roseate spoonbills foraging within a particular location in relation to a given nest. The value is computed based on distance from the nest location variable.

- Prey Availability Index: Varies by grid cell and daily time step. The index value ranges between 0 and 1 (inclusive), represents the likelihood of spoonbill prey being available. The value is computed based on a function of the water depth.

- Prey Abundance and Availability Index: Varies by grid cell and daily time step. The index value ranges between 0 and 1 (inclusive), and represents the total biomass and availability of biomass of fish that are prey for roseate spoonbills. The value is computed based on a function of the prey availability and biomass indexes.

- Habitat Suitability Index (HSI): Varies by grid cell and daily time step. The index value ranges between 0 and 1 (inclusive), and represents the response of roseate spoonbills to changes in environmental variables (for example, water depth or fish biomass). The value is computed based on a function of the prey abundance and availability and foraging proximity indexes.

- Landscape HSI: Varies by daily time step. It is an average of HSI values for the top 23 percent of cells in terms of quality. The landscape HSI value represents the highest quality foraging areas available to spoonbills.

\section{Model Process Overview}

The process of calculating HSI values for roseate spoonbills is dependent on other various outputs being computed in the model; therefore, some order dependencies exist within the model execution. The model process steps for each model run are as follows:

1. Calculate the nest proximity values for entire grid. This grid will be a static grid with no time steps. The values are the distance, in meters, of each cell from the given nest location being used in the model.

2. Calculate the foraging proximity index values for the entire grid. This grid will be a static grid with no time steps. 
3. For each time step in the model:

a. Save a water depth output grid in centimeters.

b. Calculate prey availability index and save to prey availability output grid.

c. Calculate prey abundance and availability index and save to prey abundance and availability output grid.

d. Calculate habitat suitability index and save to HSI output grid.

4. Calculate the average Landscape HSI values using the top 23 percent of HSI value cells for each time step. Save to static comma separated values (.csv) file.

\section{Model Requirements}

Inputs - A number of input files are needed to generate the model results. These inputs are listed and generically described in table 3 . The input column contains the name of the input to be used. The time resolution column describes the generalized time resolution of the input; in this case, time step" denotes that the input has values which change along some regular time interval (for example, daily, weekly, monthly, etc.), and -static" means that the input has a single set value that does not change. The units column describes the meaning of the values in the input; for example, a water depth value of 0.5 meters $(\mathrm{m})$ would mean that the water was $50 \mathrm{~cm}$ deep in that location. The type column denotes the nature of the input. In this case, -map" means that the input is a map or series of maps, and table means that the input is tabular data.

Table 3. Inputs needed to generate spoonbill model results.

\begin{tabular}{llll}
\hline \multicolumn{1}{c}{ Input } & \multicolumn{1}{c}{ Time resolution } & \multicolumn{1}{c}{ Units } & \multicolumn{1}{c}{ Type } \\
\hline Water Depth & Time Step & Meters & Map \\
Biomass Index & Time Step & None (Index) & Map \\
Nest Location & Static & Coordinates & Table \\
\hline
\end{tabular}

All inputs of the -rmp" type must have the exact same shape, scale, geographic location, and coordinate system for the model to work as formulated in this document. In addition, all inputs with a value of time step" in the -ime resolution" column must cover exactly the same time steps. All inputs must have data whose values are in the units denoted in the - nits" column for the formulation of the model contained in this document to be directly implementable as it exists. Finally, any input that has -oordinates" in the -nits" column must contain values whose coordinate system is the same as the coordinate system of inputs with a value of -map" in the -xpe" column. If any of the above is not true, this document must be reformulated to take the differences into account before the model can be adapted.

Outputs-A number of outputs are produced by the model. Some of these outputs are model results, whereas other outputs exist to verify the model results and to examine the causes and factors which contributed to the results obtained. The outputs produced by the model are listed and generally described in table 4. 
Table 4. Outputs to be produced by the spoonbill model.

\begin{tabular}{llll}
\hline \multicolumn{1}{c}{ Output } & \multicolumn{1}{c}{ Inputs } & \multicolumn{1}{c}{ Time resolution } & Type \\
\hline $\begin{array}{l}\text { Foraging Proximity Index } \\
\text { Prey Availability Index }\end{array}$ & Nest Location & Static & Map \\
$\begin{array}{l}\text { Prey Abundance \& } \\
\text { Availability Index }\end{array}$ & $\begin{array}{l}\text { Prey Availability Index, } \\
\text { Biomass Index }\end{array}$ & Time Step & Map \\
$\begin{array}{l}\text { Habitat Suitability Index } \\
\text { (HSI) }\end{array}$ & $\begin{array}{l}\text { Prey Abundance \& } \\
\text { Availability Index, Foraging } \\
\text { Proximity Index }\end{array}$ & Time Step & Map \\
Landscape HSI & Habitat Suitability Index & Static & Table \\
\hline
\end{tabular}

The Output column of table 4 contains the name of the output to be produced. The method by which each of these was produced is described next. The -riputs" column of table 4 lists the items that compose the output; for example, the Prey Abundance \& Availability Index is a function of the Prey Availability Index and Biomass Index data, and whenever the Prey Availability Index or Biomass Index change, the Prey Abundance \& Availability Index will also change. The -ime resolution" column describes the time resolution upon which the results are generated: time step" denotes that the output will be generated with the same time resolution as the input files that go into producing it (for example, if - ater depth" data was daily, then the Prey Availability Index would also be daily, since the Prey Availability Index is a function of the - ater depth" data), and -static" denotes that the output will be generated exactly once for each run of the model. The $\rightarrow$ tpe" column denotes the nature of the output. In this case, -map" means that the output is a map or series of maps, and table means that the output is tabular data. Note that all of these outputs with -map" in the -tpe" column will have the same exact shape, scale, geographical location, and coordinate system as the input layers with -map" in the -xpe" column.

Foraging Proximity Index - The Foraging Proximity Index is a map, which is a function of the - ast location" input (fig. 2). A single Foraging Proximity Index map will be generated for each run of the model. This map is generated by applying the foraging proximity rules that are defined by the minimum distance from the centroid of each cell in the Foraging Proximity Index output map to any nest location contained in the - est location" input map (table 1). 


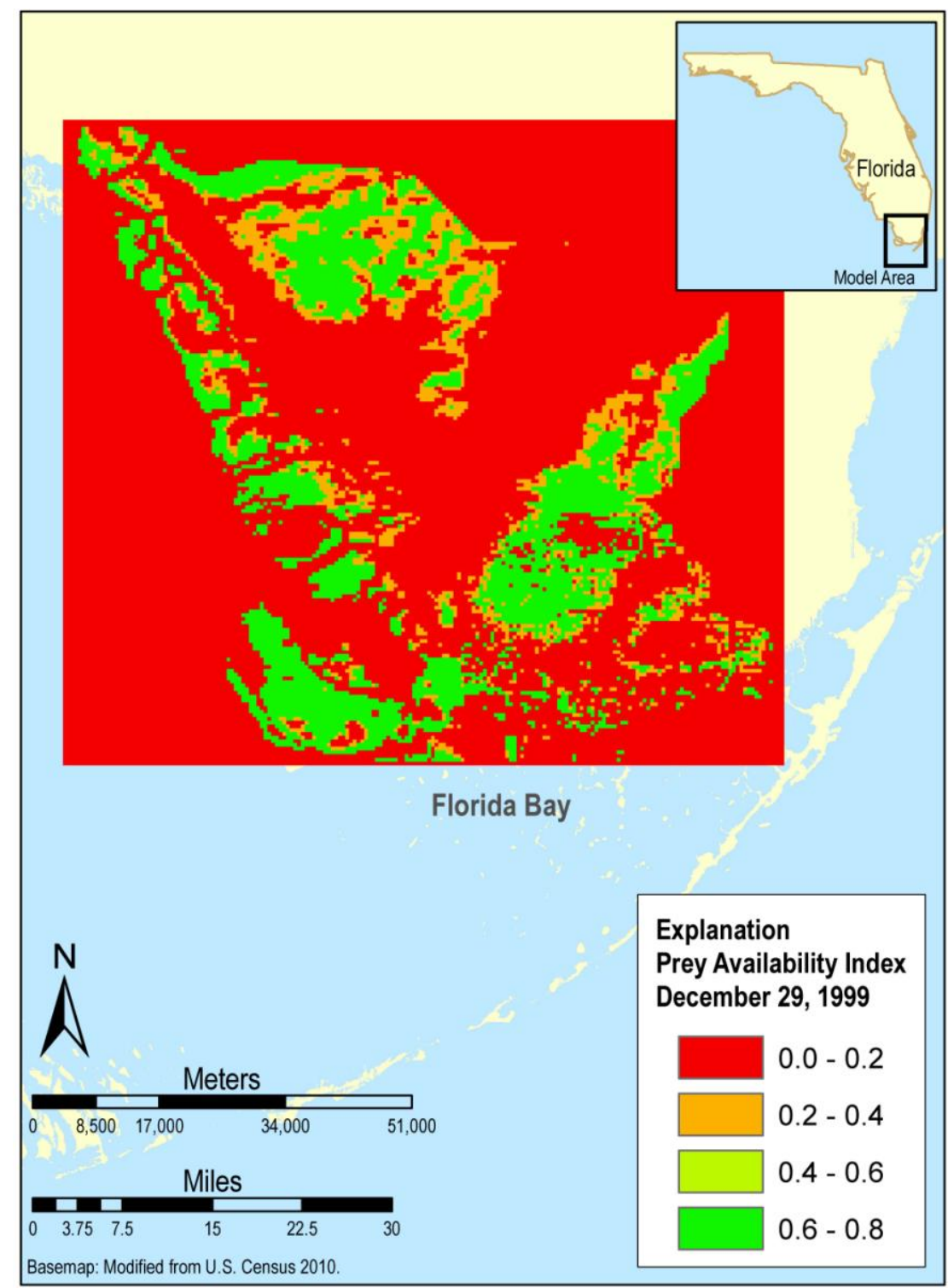

Figure 3. Map showing output from the Prey Availability Index for the spoonbill model on December 29, 1999. Green indicates higher index values and red represents lower index values.

Prey Availability Index - The Prey Availability Index is a map that is a function of the - ater depth" input (fig. 3). A Prey Availability Index time step will be generated for each — time step by applying the prey availability rules to each cell of the - vater depth" input map and placing the result in the corresponding cell of the Prey Availability Index output map for the time step. If a cell has water depth:

$<-20 \mathrm{~cm}$, it receives an Index value of 0;

$>-20$ and $<-10 \mathrm{~cm}$, it receives an Index value of 0.75 ;

$>-10$ and $<6 \mathrm{~cm}$, it receives an Index value of 1 ;

$>6$ and $<13.1 \mathrm{~cm}$, it receives an Index value of 0.75 ;

$>13.1$ and $<20 \mathrm{~cm}$, it receives an Index value of 0.25 ; and

$>20 \mathrm{~cm}$, it receives an Index value of 0 . 


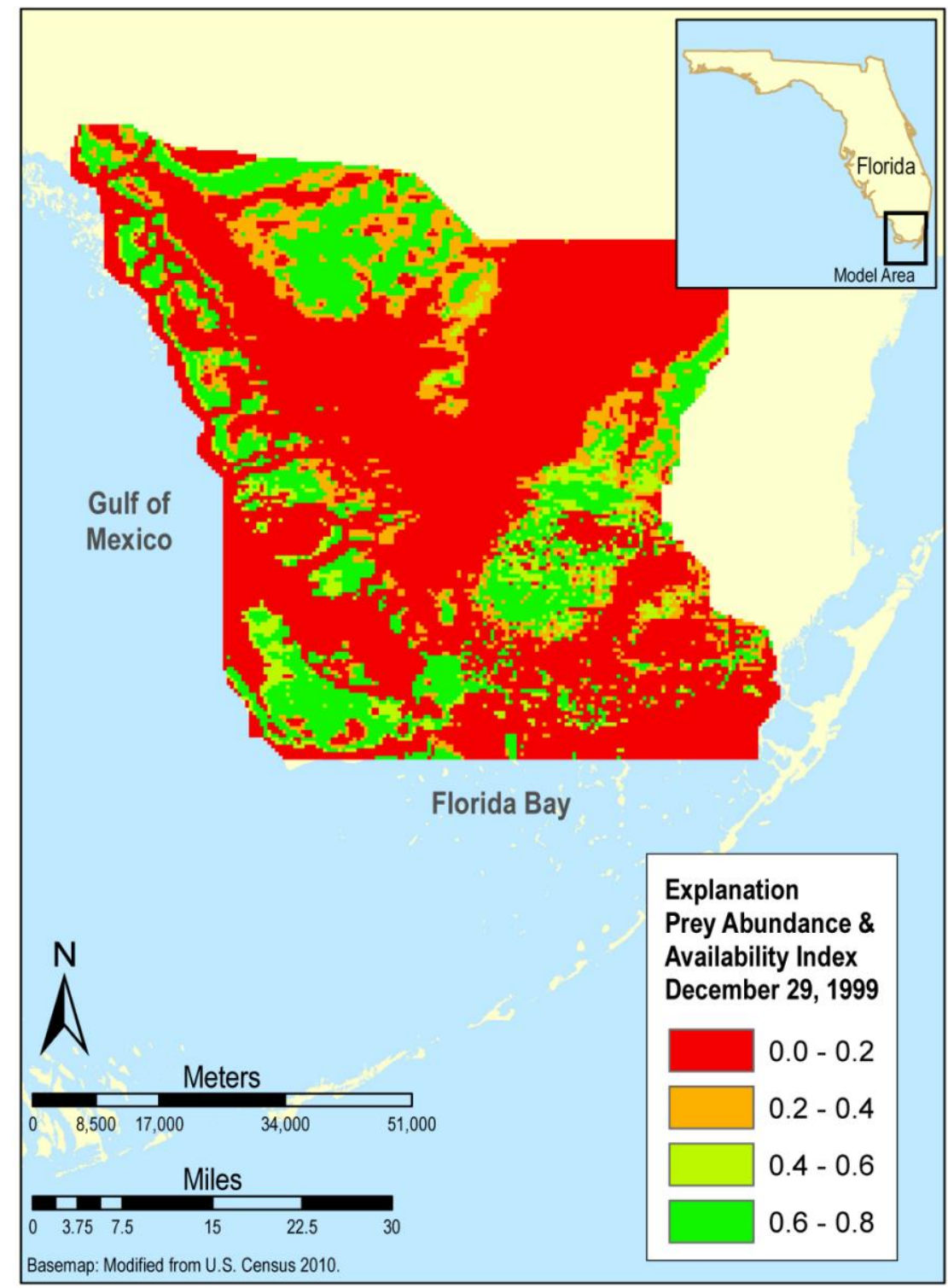

Figure 4. Map showing output from the Prey Abundance \& Availability Index for the spoonbill model on December 29. 1999. Green indicates higher index values and red represents lower index values.

Prey Abundance \& Availability Index - The Prey Abundance \& Availability Index is a map that is a function of the Prey Availability Index and Biomass Index (fig. 4). A Prey Abundance \& Availability Index time step will be generated for each time step of the Prey Availability Index and Biomass Index. The Prey Abundance \& Availability Index for a given time step is defined by equation 3. 

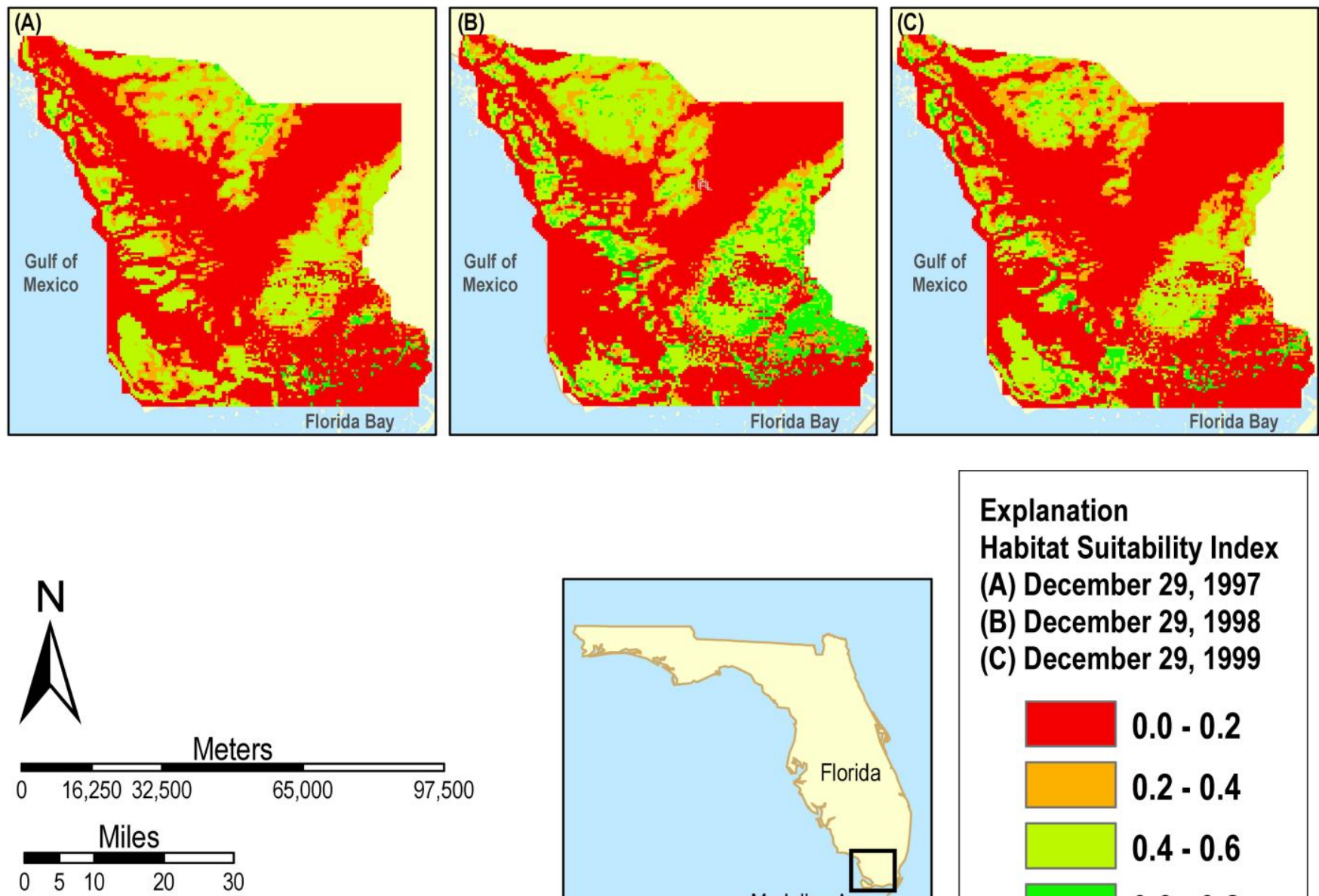

Basemap: Modified from U.S. Census 2010.

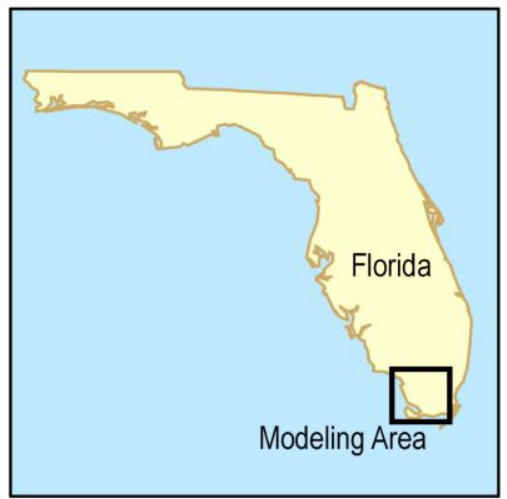

\section{Explanation \\ Habitat Suitability Index}

(A) December 29, 1997

(B) December 29, 1998

(C) December 29, 1999

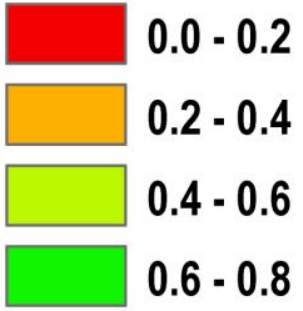

Figure 5. Map showing output from the Habitat Suitability Index (HSI) for the spoonbill model showing the HSI values changing through time on A, December 29, 1997; B, December 29, 1998; and C, December 29, 1999. Green indicates higher index values and red represents lower index values.

Habitat Suitability Index - The Habitat Suitability Index is a map that is a function of the Prey Abundance \& Availability Index and Foraging Proximity Index (fig. 5). A Habitat Suitability Index time step will be generated for each time step of the Prey Abundance \& Availability Index and Foraging Proximity Index. The Habitat Suitability Index for a given time step is defined by equation 4 .

Landscape HSI-The Landscape HSI is a table of output generated as a function of the Habitat Suitability Index. A single Landscape HSI table is generated for each run of the model (appendix 1, in Microsoft Excel file). The table contains two columns and a single row for each time step of the Habitat Suitability Index. The first column contains the date of a Habitat Suitability Index time step, and the second column contains the arithmetic mean of the 23 percent (rounded up) of real-valued cells (by cell count, not cell area) having the highest values contained within that time step of the Habitat Suitability Index map. 


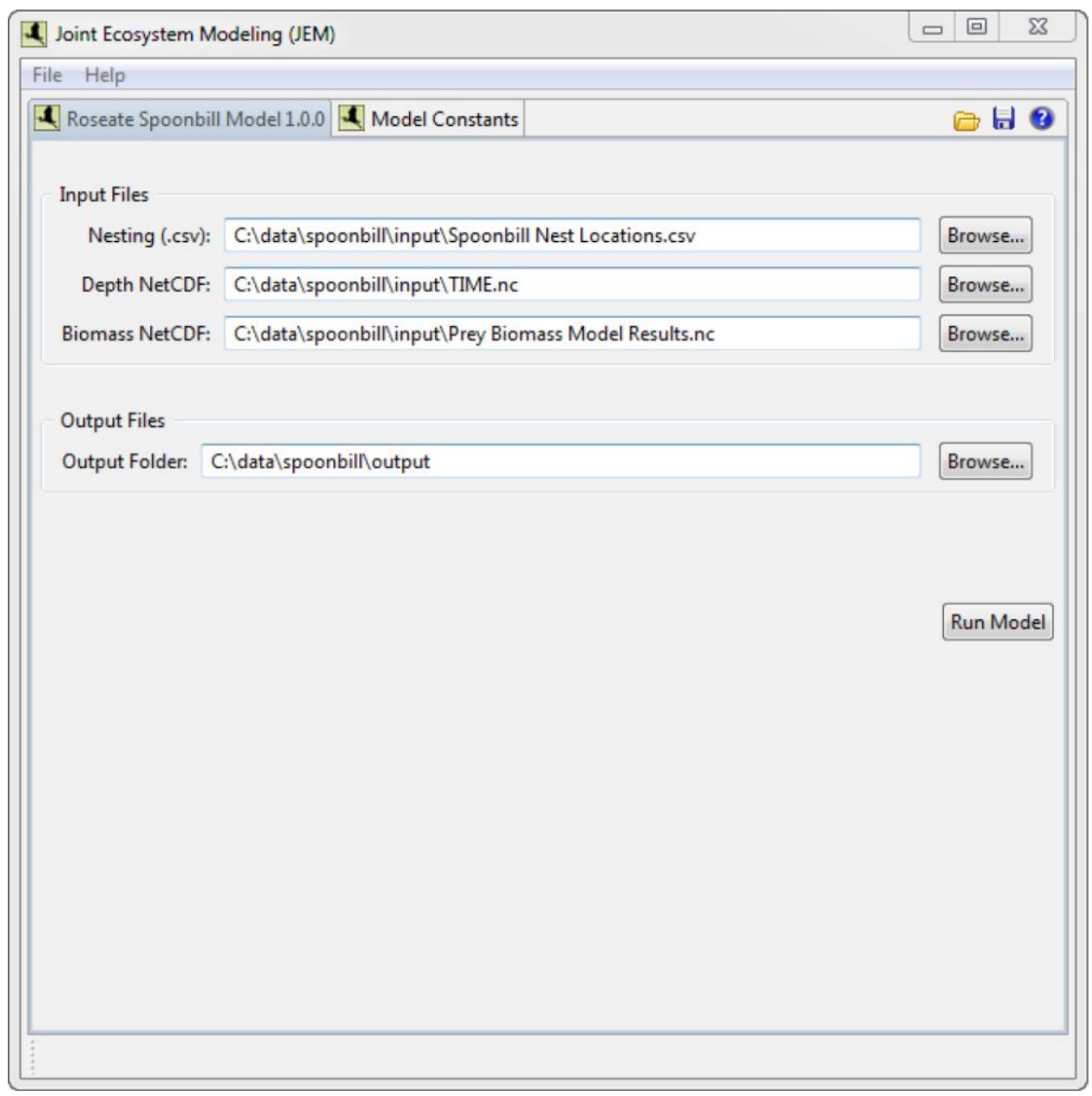

Figure 6. Application screenshot of files required to run the spoonbill model and produce output.

\section{Model Application User's Guide}

Requirements - The Roseate Spoonbill Model application is written in Java using version 1.6.0_05 of the Java libraries. Consequently, version 1.6.0_05 or later of the Java Runtime Environment must be installed to run the application, which uses version 4.0 of the Java NetCDF libraries - these are included in the executable archive for convenience. The program uses relatively little memory, but at least 1 gigabyte (GB) of unallocated system memory is required for the application's use to ensure ample memory is available and minimize the chance of running out of memory. The program should work on any processor that supports the Java Runtime Environment, although faster processors speeds result in shorter run times. For most data sets, it would be fairly reasonable to expect that the application will generate roughly $1 \mathrm{~GB}$ of output data, so there should be at least $1 \mathrm{~GB}$ of free hard drive space available on the drive containing the output directory for each year of data to be processed. For larger data sets, more space will be required for each year.

Usage - The Roseate Spoonbill Model application is packaged as a compressed -zip" file. To run the application, the user must first extract all files locally and then double-click the JEMSpoonbillModel.exe file. The model interface will display, allowing the user to either load a preexisting model parameter settings file (in extensible markup language, XML) or manually set the model variables, including input and output folder paths (fig. 6). 
Settings - The settings file is an XML file containing specific model parameters that can load the application with preset values for model variables, constants, and paths. The application allows the user to save model variable and path modifications as new settings files, or to load previously saved settings files.

Sample XML Settings File-The following is a sample XML settings file for a complete model run. The file, variable, and dimension names are just examples and may differ depending upon the input data used.

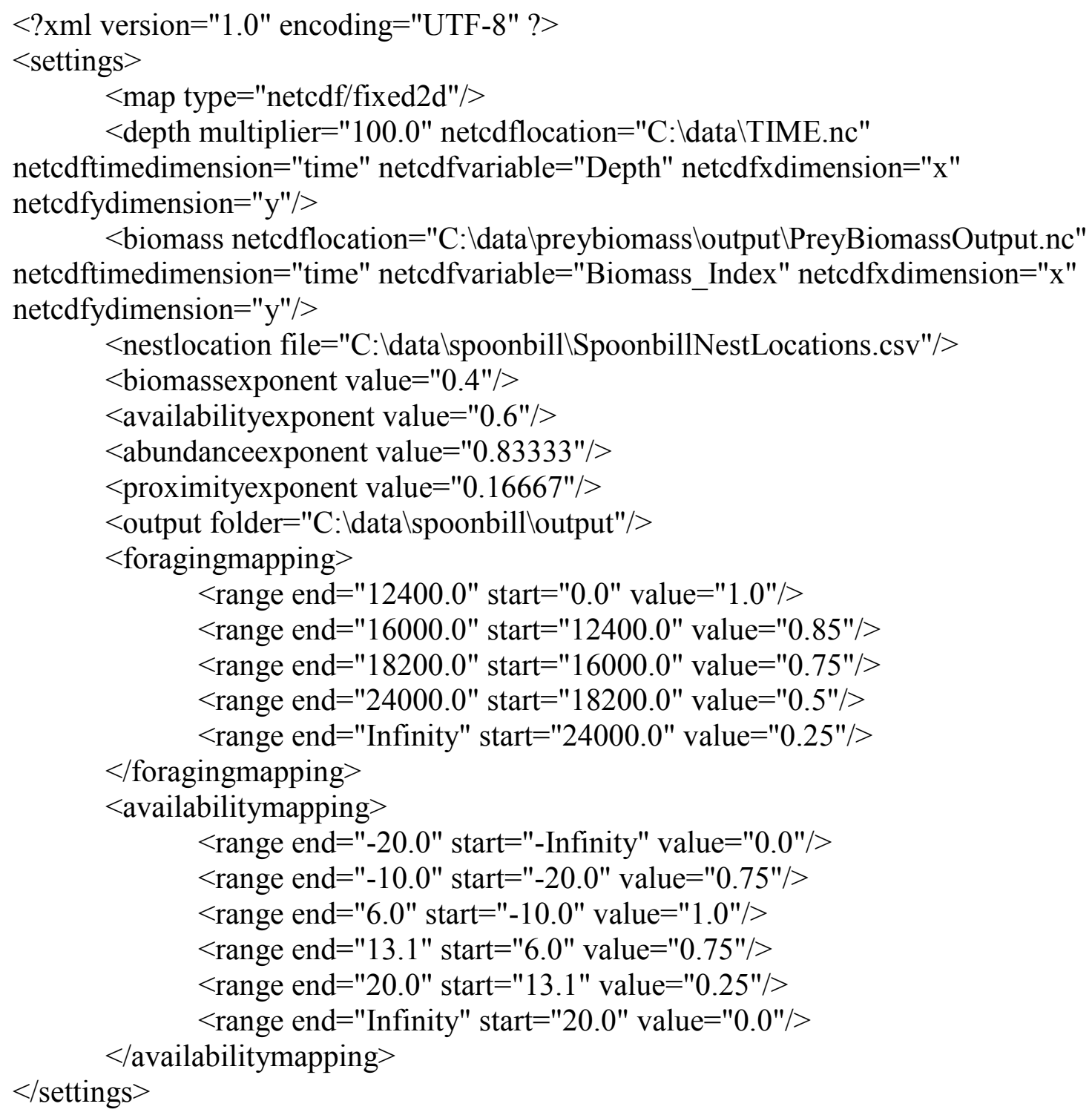

Map Element - The root element of the settings XML file must contain an element named map." This element must have at least one attribute named type," which should be a string containing the type of data to be used in the model. Currently the only type supported by the model application is netcdf/fixed2d, which denotes that the input data is contained in fixed two-dimensional grids in the NetCDF file format. 
Depth Element-The root element of the XML file must contain an element named -depth." This element must have at least five attributes. The depth element must have an attribute named -netcdflocation," which should be a string with the location of a NetCDF file containing a variable with water depths in meters. The depth element must also have an attribute - netcdfvariable," which should be a string containing the name of the variable for water depth in the NetCDF file. The depth element must also have an attribute named +netcdfxdimension," which should be a string containing the name of the $\mathrm{x}$ dimension for the water depth variable in the NetCDF file, an attribute named netcdfydimension," which should be a string containing the name of the y dimension for the water depth variable in the NetCDF file, and an attribute named netcdftimedimension," which should be a string containing the name of the time dimension for the water depth variable in the NetCDF file. The depth element may optionally have an attribute named -multiplier," which contains a floating point number by which all water depth input cells are to be multiplied before they are used (for example, if the NetCDF input file had depths in meters, a multiplier of 100 could be used to ensure the depths were in centimeters for proper execution of the model application).

Biomass Element-The root element of the XML file must contain an element named biomass." This element must have at least five attributes. The biomass element must have an attribute named -netcdflocation," which should be a string with the location of a NetCDF file containing a biomass index variable that contains cells with values between 0 and 1 , inclusively. The biomass element must also have an attribute named +netcdfvariable," which should be a string containing the name of the variable for biomass index in the NetCDF file. The biomass element must also have an attribute named -netcdfxdimension," which should be a string containing the name of the $\mathrm{x}$ dimension for the biomass index variable in the NetCDF file, an attribute named -netcdfydimension," which should be a string containing the name of the y dimension for the biomass index variable in the NetCDF file, and an attribute named netcdftimedimension," which should be a string containing the name of the time dimension for the biomass index variable in the NetCDF file.

Nest Location Element-The root element of the XML file must contain an element named -nestlocation." This element must have a single attribute named file," which should be a string containing the location of a file with a list of nest locations. This file should be a text file with at least one line (and probably many lines), where each line represents a single nest and has the following format:

$<$ ID $>,<$ Easting $>,<$ Northing $>,<$ Location $>$

where $<\mathrm{ID}>$ is a unique numerical identifier for the nest, $<$ Easting $>$ is a floating point number representing the easting of the nest's location in the same coordinate system as the input maps, $<$ Northing $>$ is a floating point number representing the northing of the nest's location in the same coordinate system as the input maps, and $<$ Location $>$ is text that briefly enumerates the location where the nest was found (for example, Alligator Bay).

Foraging Proximity Mapping Element-The root element of the XML file must contain an element named foragingmapping." This element represents the function used in the Foraging Proximity Index named $f_{\text {Foraging Proximity }}$ in the Roseate Spoonbill Model Requirements Document and must contain at least one range element. Each range element must have at least three attributes. The range element should have an attribute named -start" and an attribute named -end," which both are strings containing a floating point number or -Infinity." Finally, the range element should also have an attribute named $\forall$ alue," which is a string containing a floating point number.

Availability Mapping Element-The root element of the XML file must contain an element named availabilitymapping." This element represents the function used in the Prey Availability Index named $f_{\text {Availability }}$ in the Roseate Spoonbill Model Requirements Document and must contain at least 
one range element. Each range element must have at least three attributes. The range element should have an attribute named -start" and an attribute named -end," which both are a string containing a floating point number or --Infinity." Finally, the range element should also have an attribute named ralue," which is a string containing a floating point number.

Biomass Exponent Element-The root element of the XML file must contain an element named biomassexponent." This element must have an attribute named $\forall$ alue," which contains a floating point number that represents the exponent of the Biomass Index factor of the Prey \& Abundance Availability Index of the Roseate Spoonbill Landscape Habitat Suitability Index Model Requirements section.

Availability Exponent Element-The root element of the XML file must contain an element named availabilityexponent". This element must have an attribute named $\forall$ value”, which contains a floating point number that represents the exponent of the Prey Availability Index factor of the Prey \& Abundance Availability Index of the Roseate Spoonbill Landscape Habitat Suitability Index Model Requirements section.

Abundance Exponent Element-The root element of the XML file must contain an element named abundanceexponent". This element must have an attribute named $\forall$ alue", which contains a floating point number that represents the exponent of the Prey Abundance \& Availability Index factor of the Habitat Suitability Index of the Roseate Spoonbill Model Requirements section.

Proximity Exponent Element - The root element of the XML file must contain an element named proximityexponent". This element must have an attribute named $\forall$ alue", which contains a floating point number that represents the exponent of the Foraging Proximity Index factor of the Habitat Suitability Index of the Roseate Spoonbill Model Requirements section.

Output Element - The root element of the XML file must contain an element named - $\rightarrow$ utput". This element must have an attribute named folder", which is a string containing the destination path of the NetCDF files to be created or overwritten where spatial model results are to be stored.

Output - The model application produces a separate NetCDF output file for each model input and output described in the Model Requirements section. The model results will contain the same range of time steps as the input files. A .csv output text file is also produced that may be opened in most modern spreadsheet software without alteration. This file contains a table containing the Landscape HSI output values and will have the following form:

$<$ Date $>,<$ Value $>$

where $<$ Date $>$ is the date of a time step of the Landscape HSI output, and $<$ Value $>$ is the value of the Landscape HSI output for that date.

\section{Model Specifications}

Application Design - The model application was originally developed to generate model results for the TIME model hydrology and salinity data (Wang and others, 2007), but was constructed using a design that would allow for future extension of the model application to run with other hydrology and salinity data. The model application was built using an extensible software plug-in framework that allows for future integration with various other data manipulation and viewer applications built using similar architecture.

Mesh Class - The Mesh class is an abstraction of any set of data that can be represented as an ordered list of cells containing floating point numbers. The orientation, arrangement, and shape of the data is irrelevant, with the provision that any two Meshes representing the same set of data should order the list of cells in exactly the same way.

Implementations of Mesh must supply a very minimal set of methods (though the Mesh class contains several useful methods for convenience that are already implemented). Those methods that 
support basic interaction with Mesh data are passed an index, which is the location of the cell in the ordered list. The getCell method returns the floating point value contained in the cell at the location specified by the passed index. The setCell method takes a floating point value and assigns it to the cell at the location specified by the passed index. The getLength method returns the number of cells contained in the Mesh. The getCellCentroid returns the location of the centroid of the cell in the geographic coordinate system of the data. Finally, the clone method returns an exact duplicate of the Mesh. All of the model decision rules can be implemented upon any sort of data that can be represented as a Mesh using these five methods.

MeshReader and MeshWriter Interfaces - Because a function that maps the underlying data to a list of cells depends upon the nature of the data, a Mesh cannot be created directly. Likewise, because it is impossible to know the actual shape and arrangement of the underlying data using the five previously described methods, a Mesh cannot be stored directly to some medium, such as to disk. To resolve these issues, the MeshReader and MeshWriter interfaces are provided for the loading and saving of Mesh data, respectively.

An implementation of the MeshReader interface only needs to implement a single method named toad". The load method is passed a GregorianCalendar that contains the date of the data to be fetched, which may be null if the data to be fetched has no time component); a String containing the name of the data to be fetched; and an array of Objects that contain any additional data required to populate the Mesh, which is returned by the method. The meaning of the additional data passed to the method is internal to the particular implementation of the MeshReader and does not necessarily have any external significance.

Likewise, an implementation of the MeshWriter interface only needs to implement a single method named -save". In this case, the save method is passed the Mesh to be stored, a GregorianCalendar that contains the date of the data to be stored (which may be null if the data to be stored has no time component), a String containing the name of the data to be stored, and an array of Objects that contain any additional data required to store the Mesh. The meaning of the additional data passed to the save method is internal to the particular implementation of the MeshWriter, and does not necessarily have any external significance.

Processor Class - The Processor class is the component that implements the model decision rules. It is given a series of MeshReaders (and the other data needed to invoke the load method) for each of the various model inputs and one to load the outputs for aggregation, a MeshWriter to store the model outputs, the time step dates for which the model is to be run, and the other parameters needed to generate the model results. The Processor class deals solely with Meshes, and does not interact with the underlying data in any way, which is what allows the Processor class to be used with any data set that can be converted into Meshes. The Processor class is responsible solely for generating model results rather than verifying that inputs are in the correct format, and does no testing to that end; format checking is handled by the SpoonbillModel class, described next.

SpoonbillModel Class - The SpoonbillModel class gathers and tests the data necessary for the Processor class to generate model results. In order to meaningfully do this, the SpoonbillModel interacts with descendants of Meshes as their subtype, not abstractly. The precise restrictions and requirements imposed upon the input data by the SpoonbillModel class depend upon the input data, and are described fully in the applicable section on input data.

Current Implementation: Fixed 2D Arrays_-The Roseate Spoonbill Model application is written to generate results for fixed two-dimensional regular rectilinear float arrays in NetCDF files with a daily time resolution. There are three inputs to the model application: water depth, biomass index, and nest locations. 
Map Requirements and Restrictions-All of the inputs other than nest locations contain map data. The water depth and biomass index inputs all have the following requirements and restrictions:

- A daily time resolution

- At least one time step of data

- All linear units must be meters

- There must be at least one cell in every map

- All cells must have the same width and height

- All time steps and inputs must have an identical set of cells, although the assigned values will be different

- Both of these inputs must share at least one time step

- All data for a single input must be contained in a variable in a single NetCDF file, where the variable has three dimensions, one of which must be time, and contains floats

- All data must be in the same projection

Nest Locations Requirements and Restrictions-The nest locations input must be a .csv text file which contains four columns, and at least one row, where each row represents the locations of a nest. The first column of each row should contain a unique identifier for the nest location. The second column must contain the easting of the nest location in UTM zone 17R. The third column must contain the northing of the nest location in UTM zone 17R. The fourth column should contain the general location of the nest.

Fixed 2D Array Implementation Classes - A number of classes were developed to handle the reading of fixed two-dimensional grid data from two- and three-dimensional NetCDF variables, the writing of fixed two-dimensional grid data to two and three-dimensional NetCDF variables, and the storage of fixed two-dimensional grid data in memory, all within the context of the Mesh architecture.

Fixed2DGrid Class - The Fixed2DGrid class is a simple implementation of the Mesh class intended to store regular, rectilinear, fixed two-dimensional grids. The size and dimensions of a Fixed2DGrid may not be changed once it has been created, but the values contained in the cells can change. This class has no exposed methods other than what is required by its Mesh superclass, and has no exposed constructor.

Fixed2DGridNetCDFReader Class - The Fixed2DGridNetCDFReader class is an implementation of the MeshReader class intended to read regular, rectilinear, fixed two-dimensional grids from two- and three-dimensional NetCDF variables. When a Fixed2DGridNetCDFReader is instantiated, it must be passed a valid NetcdfFile object from which it will read data. The load method, implemented from MeshReader returns a Fixed2DGrid from the passed NetcdfFile object. The GregorianCalendar object passed to the load method is the date of the Fixed2DGrid to be fetched from the NetCDF file (or null if the NetCDF variable has no time dimension). The String passed to the load method contains the name of the variable in the NetCDF file containing the data array to access. The additional parameters passed to the load method must contain two to three String objects. The first object must be a String containing the name of the $\mathrm{x}$ (easting) dimension of the NetCDF variable, and the second must be a String containing the name of the $y$ (northing) dimension of the NetCDF variable. The third object must be a String containing the name of the time dimension of the variable, if the passed GregorianCalendar is non-null (and is ignored otherwise).

Fixed2DGridNetCDFWriter Class - The Fixed2DGridNetCDFWriter class is an implementation of the MeshWriter class intended to write Fixed2DGrids to two- and three-dimensional NetCDF variables. When a Fixed2DGridNetCDFWriter is instantiated, it must be passed a valid NetcdfFileWriteable object to which it will write data. The save method implemented from MeshWriter takes a Mesh object as a parameter, which must be the Fixed2DGrid that is to be stored in the NetCDF 
file. The GregorianCalendar object passed to the save method is the date of the Fixed2DGrid to be stored in the NetCDF file (or null if the NetCDF variable has no time dimension). The String passed to the save method contains the name of the variable in the NetCDF file to which the Fixed2DGrid is to be written. The additional parameters passed to the save method are the same as those passed to the load method, and must contain two to three String objects. The first object must be a String containing the name of the $\mathrm{x}$ (easting) dimension of the NetCDF variable, and the second must be a String containing the name of the $y$ (northing) dimension of the variable. The third object must be a String containing the name of the time dimension of the NetCDF variable if the passed GregorianCalendar is non-null (and is ignored otherwise).

Outputs - The model application produces a separate NetCDF output file for each model input and output described in the Model Requirements section. Tabular Landscape HSI results are stored in a single .csv file. Model results are generated for the range of time steps shared by all inputs (in other words, the intersection of the time steps of all inputs).

NetCDF Files - The CF-1.0 compliant NetCDF output files of the model application contain variables for the model inputs and outputs described in the Roseate Spoonbill Model Requirements Document, as well as some variables that represent intermediary values in calculations and metadata. The variables in the output NetCDF files which correspond to the outputs and inputs described in the Roseate Spoonbill Model Requirements section are described by table 5 where (1) NetCDF Variable Name is the name of the variable in the NetCDF output file, (2) Model Requirements Name is the name of the output in the Roseate Spoonbill Model Requirements section, (3) Units is the units of the values in the cells of the outputs, and (4) Type indicates whether the output is an input or output in the Roseate Spoonbill Model Requirements section.

Table 5. Variables in the output NetCDF file which correspond to the spoonbill model inputs and outputs.

\begin{tabular}{llll}
\hline \multicolumn{1}{c}{ NetCDF variable name } & \multicolumn{1}{c}{ Model requirements name } & \multicolumn{1}{c}{ Units } & \multicolumn{1}{c}{ Type } \\
\hline Water_Depth & Water Depth & Meters & Input \\
Biomass_Index & Biomass Index & None (Index) & Input \\
Foraging_Proximity_Index & Foraging Proximity Index & None (Index) & Output \\
Prey_Availability_Index & Prey Availability Index & None (Index) & Output \\
Prey_Abundance_And_Availability_Index & Prey Abundance \& Availability Index & None (Index) & Output \\
Habitat_Suitability_Index & Habitat Suitability Index & None (Index) & Output \\
\hline
\end{tabular}

In addition to the aforementioned outputs, another output NetCDF file is produced that contains a variable not explicitly described by the requirements. The variable is named Nest_Proximity", and is a map with no time component whose cells contain distances in meters from the cell's centroid to the nearest nest location, which can be used to verify that the Foraging Proximity Index is calculated properly (as well as to act as some record of the nest locations which were used as inputs). The NetCDF files also contain a variable named transverse_mercator", which contains the metadata to indicate that the map variables in the NetCDF file are in UTM zone 17R.

The output NetCDF files contain three dimensions: $x, y$, and time. Every variable for a map in a NetCDF file has the $\mathrm{x}$ and $\mathrm{y}$ dimensions. The variables for the maps in a NetCDF file that have a time component also have the time dimension.

CSV File - The second piece of output generated by the model application is a Landscape HSI .csv file, which corresponds to the Landscape HSI output in the Roseate Spoonbill Model Requirements Document. This .csv file has two columns, the first of which contains a date, and the second of which 
contains the Landscape HSI output for that date. The .csv file contains a row for each date for which a Landscape HSI is generated. These values are indices and consequently have no units.

Data Set: The TIME Model-The model application was originally developed for the purpose of using TIME model hydrology and salinity as inputs (Wang and others, 2007).

Water Depth-The water-depth input data is from the TIME model hydrology (Wang and others, 2007). Water depth data is contained in a series of three-dimensional float arrays in a NetCDF file, and covers the time period from January 1, 1996, to December 30, 1999, with a daily resolution. The received data has a spatial extent covering the area from the coordinates $(461000,2779000)$ to (557500, 2865500) of UTM zone 17R. Each cell of the received data is a square measuring $500 \mathrm{~m}$ per side, and the total area is 194 cells wide by 174 cells tall. The water-depth data values contained in the cells are measured in meters.

Biomass Index - The biomass index input data were generated using the Estuarine Prey Fish Biomass Model (Romañach and others, 2011). The particular inputs used for this model were generated by using the aforementioned TIME model water depth and the TIME model salinity data as inputs to the Prey Biomass Model Application. The biomass index data are contained in a series of three-dimensional float arrays in a NetCDF file, and cover the time period from October 26, 1996, to December 30, 1999, with daily resolution. The data have a spatial extent covering the area from the coordinates $(461000$, $2779000)$ to $(557500,2865500)$ of UTM zone $17 \mathrm{R}$. Each cell is a square measuring 500 meters per side, and the total area is 194 cells wide by 174 cells tall. The indices assigned to cells containing biomass index data are weights ranging from 0 to 1 (both inclusively) and subsequently have no units.

Nest Locations - The nest locations input data are latitude/longitude pairs recorded by J. Lorenz (written commun., 2011) and then converted to its current form. Aest locations" input data are a .csv text file containing four columns: ID, Easting, Northing, and Location. ID is a unique numerical identifier for the nest location, Location is a description of the location where the nest resides, and the point (Easting, Northing) is the location of the nest in UTM zone 17R coordinates.

\section{Future Use}

A number of potential changes may need to be made to the model application in the future for several reasons. This section addresses some of the most obvious foreseeable changes that may need to be made, and outlines the steps necessary to implement them.

Changing Model Rules-Although the model is currently in its final form with respect to the current model requirements, these requirements may change because of future discoveries or realizations by subject matter experts. In its current state, the model application allows for some flexibility with respect to changes to the model rules. If any of the weights or functions in the requirements are changed, then these may be modified directly in the configuration XML file. Any other changes to the model requirements would likely require modification or rewriting of the Processor class, and potentially the SpoonbillModel class as well.

Extending the Model Application to Support New Data Sets-The model application was designed with the realization that other data sets would be used in the future to generate model results. The Mesh/MeshReader/MeshWriter and SpoonbillModel/Processor class hierarchies were developed as support for this notion.

Known Issues - There may be issues with NetCDF variables whose time units specify a time zone other than GMT, or variables that specify a time component (other than 00:00), due to the functions of the DateUnit class in the NetCDF libraries. This function returns dates parsed to the current time zone, not the time zone specified by the file. Consequently, loaded data may appear to be offset by a day depending upon the time zone of the machine on which the application is run. 


\section{Summary and Conclusions}

The roseate spoonbill Landscape HSI model will allow users to evaluate the potential response of this key species to water management practices that are proposed as part of the Greater Everglades restoration process. Comparison to field data shows that the model is a good indicator of areas capable of supporting spoonbills.

Variations on the spoonbill model may be useful for evaluation of habitats of other ecologically and recreationally important species in the Greater Everglades region. The spoonbill model includes a prey-fish biomass availability component that provides the constraint that appropriate foraging conditions have to be met. Foraging conditions modeled for spoonbills are similar to those required by other key species such as the threatened American crocodile, alligators, other wading birds, and piscivorous fishes. Future directions will include modifications to allow for similar evaluation of other key species habitats in the region to aid in restoration planning.

\section{References Cited}

Barnes, T.K., Mazzotti, F.J., Pearlstine, L., and Volety, A., 2006, Ecological evaluation in coastal southwestern Florida: A Policy decision model for the blue crab (Callinectes sapidus): Florida Scientist, v. 69, p.140-151.

Bjork, R.D., and Powell, G.V.N., 1994, Relationships between hydrologic conditions and quality and quantity of foraging habitat for Roseate Spoonbills and other wading birds in the C-111 basin: Final report to the South Florida Research Center, Everglades National Park, Homestead, Florida.

Gawlik, D.E., 2001, Wood Stork and White Ibis and Small Heron Habitat Suitability Indices: South Florida Water Management District report, West Palm Beach, Fla.

Gawlik, D.E., 2002, The effects of prey availability on the numerical response of wading birds: Ecological Monographs, v. 72, p. 329-346.

Light, S.S., Dineen, J.W., 1994, Water control in the Everglades: A historical perspective, in Davis S.M., and Ogden, J.C., eds., Everglades: The Ecosystem and Its Restoration: Delray Beach, Fla., St. Lucie Press.

Lorenz, J.J., 1999, The response of fishes to physicochemical changes in the mangroves of northeast Florida Bay: Estuaries, v. 22, p. 500-517.

Lorenz, J.J., 2000, Impacts of water management on Roseate Spoonbills and their piscine prey in the coastal wetlands of Florida Bay: Coral Gables Fla., University of Miami Ph.D. Dissertation.

Lorenz, J.J., McIvor, C.C., Powell, G.V.N., Frederich, P.C., 1997, A drop net and removable walkway for sampling fishes over wetland surfaces: Wetlands v. 17, p. 346-359.

Lorenz, J.J., Ogden, J.C., Bjork, R.D., and Powell, G.V.N., 2002, Nesting patterns of Roseate Spoonbills in Florida Bay 1935-1999: Implications of landscape scale anthropogenic impacts, in Porter, J.W., and Porter, K.G., eds., The Everglades, Florida Bay, and Coral Reefs of the Florida Keys: An ecosystem sourcebook: Boca Raton, Fla., CRC Press, p 563-606.

McIvor, C.C., J.A. Ley \& R.D. Bjork, 1994. Changes in freshwater inflow from the Everglades to Florida Bay including effects on the biota and biotic processes: A review, in Davis, S.M., and Ogden, J.C., eds, Everglades: The Ecosystem and Its Restoration: Delray Beach, Fla., St. Lucie Press, p 117146.

Powell, G.V.N., 1987, Habitat use by wading birds in a subtropical estuary: Implications of hydrography: Auk v. 104, p. 740-749. 
Romanach, S., Conzelmann, C., Daugherty, A., Lorenz, J.L., Hunnicutt, C., and Mazzotti, F.J. 2011, Joint Ecosystem Modeling (JEM) Ecological Model Documentation Volume 1: Estuarine Prey Fish Biomass Availability v1.0.0: U.S Geological Survey Open-File Report 2011-1272, 20 p.

Smith, J.P., and Collopy, M.W., 1995, Colony turnover, nest success and productivity, and causes of nest failure among wading birds (Ciconiiformes) at Lake Okeechobee Florida (1989-1992): Archives of Hydrobiology Special Issues, Advanced Limnology, v. 45, p. 287-316.

U.S. Army Corps of Engineers and South Florida Water Management District, 1999, Central and Southern Florida Project Comprehensive Review Study Final Integrated Feasibility Report and Programmatic Environmental Impact Statement: U.S. Army Corps of Engineers, Jacksonville District, Jacksonville, Fla.

U.S. Fish and Wildlife Service, 1981, Standards for the development of habitat suitability index models for use in the habitat evaluation procedures: Report ESM 103, Interagency Interdisciplinary Development Group, Division of Ecological Services, U.S. Fish and Wildlife Service, U.S. Department of the Interior, Washington D.C.

Wang, J.D., Swain, E.D., Wolfert, M.A., Langevin, C.D., James, D.E., and Telis, P.A., 2007, Application of FTLOADDS to Simulate Flow, Salinity, and Surface-Water Stage in the Southern Everglades, Florida: U.S. Geological Survey Scientific Investigations Report 2007-5010, 112 p. 